Perhaps the Georgian and Armenian versions of Proclus and Hermeias which remain are a monument of this temporary exile of the last of the new Platonists. At the foot of Mount Ararat I found, in an Armenian Monastery, two versions of the principles of theology of Proclus; of these versions the latest was a translation of a Georgian version, and had been made in the year 1400 by an Armenian priest, who added to his work a note to the effect that he believed a version to have been already made direct from the Greek in the fifth or sixth century, which version had been lost. This earlier version I found in the same library. I cannot say whether the Georgian version was made direct from the Greek, or whethcr it was translated from the early Armenian version. The work of Proclus on Causes, lost in Greek, also exists in Armenian, and, like the Principles, was very exactly translated. Both works remain in Arabic. In Armenian libraries I have also found a short treatise on the universe by the philosopher Hermeias, not, I believe, otherwise preserved. Thus the writings of Proclus have met with a vogue and popularity in the East scarcely less than that of those of Aristotle. Other monaments also remain of the zeal which the new Platonic sages of Athens could implant in their disciples from the far East. Several dialogues of Plato, among the rest the Timaeus and the Laws, are still preserved in very exact and accurate renderings in the ancient Armenian language. The translation of the Laws is a remarkable fact, and significant of the importance attached to that dialogue, which, as we hare already seen, was to form the written constitation of the new Italian settlement of Platonopolis.

\title{
THE PSYCHOLOGY OF SPORT AND PLAY.
}

\section{By A. M. OgiLtie.}

SOME people in some moods bave a fondness for rationalism of a cheap kind, and profess to wonder very much at the foolishness of other people engaging in pursuits which have no visible atility for their end, and are prompted by or nrouse feelings with which the Rationalists have no sympathy, generally because they have never actually experienced them. To persons of this class it seems mere childishness to take pleasure in knocking a ball to and fro over a net, or in hitting it with a wooden bat about a field, or in any other game of the kind; but the great majority of people, in this country at any rate, do not 
trouble themselves with such questions. Their feelings either as players or as spectators come to them as a part of their haman nature, and they engage in sports and games without question and withont the least suspicion that their character as rational beings is thereby in any way endangered. In London last, winter 20,000 people watched a football match with eager interest, and probably not one of the number ever considered what attraction to draw them all togother there could be in the sight of twenty-two men, with immense exertion, kicking sometimes an inflated leather-covered bladder, and sometimes one another. Bat if we leave out of sight the feelings which, as we probably know by experience, do exist in the minds of players and spectators, and if we put ourselves at the point of view of the strict Utilitarian and seek on a priori grounds to find a reason for such a gathering, some questionings of the kind do not seem to be so inappropriate. Our tolerance and encouragement of sports and pastimes seems mostly a result of instinct rather than of reflection, and the ordinary man if called upon in such a case to justify his love of games might for a while be at a loss to flnd a satisfactory explanation. It does not follow, however, that the love of games is really irrational, and that it should not be allowed to influence us. Instinct is in many matters a safer guide for men in general than reason, or, at any rate, than the first judgments of reason. If we search out these strong influences and instincts which prompt men to engage in sports and pastimes we find them springing from the very roots of buman nature and having an important share in its fulfilment and development.

The ordinary doctrine of the "Play Impulse" is a common-place in Psychology. Every writer points out that for the young the ordinary activities of life do not use up the whole nervous energy, as they do in the case of adults, who have to undergo the necessary labour of self-support, or, at any rate, some round of daties or occupation; and that there is, therefore, as the nerrous force accumulates, a tendency to break into spontaneous random action, uncontrolled by any settled porpose. I do not think that it is at all implied that the accumulated energy is greater in volume in the child than in the grown man, bat merely greater in relation to its ordinary channels, just as the brook overflows its banks more easily and more rapidly than the river.

The relations of the child to external things are few, and are exercised within a narrow compass. As intelligence increases the relations increase in number, and stretch out farther and farther from the Central sabject, requiring for their fulfilment more and more of the whole active force; and so the exuberant activity of childhood, aroused with little or no prorocation, changes gradually into steady 
purposefal action, or, at any rate, into the regalar pursuit of settled ends, however worthless those ends may be.

Looking at this aspect of human nature, we can easily account for the simple games of children, which of ten seem to depeud on very slight incentives to activity. Snch incentives, indeed, are not required. But we can hardly see how the organisation and practice of games and sports should so greatly increase, as we seo them do, as the necessity for them apparently grows less. Sometimes it even seems as if the natural order were reversed, when we see children's play made up of imitatious of the occupations and pursuits of gruwnup people, and adults occupied in games in which the immediate ends pursued are in themselves apparently unattractive eren to a child. The simple theory with which we started needs, therefore, some development.

Looking at our facts we see that men in general participate in sports and games in two characters, namely, as agents or players, and as spectators. At first sight it seems if those two characters were unlike, but on examination it will, I think, he found that the two really merge into one another, and that from the point of view of the psychologist the same laws govern both conditions. The contrast is, perhaps, sharpest in those sports and games in which bodily activity is involved to any great extent, as, for instance, in what we may call the great class of ball games. But in describing the feelings of the spectators of any active sport we may, I think, take it as an axiom that the feelings of the spectators are of the same kind, though differing in intensity, as the feelings of the players. They are, in fact, a reflection of those feelings, but always, of course, with certain modifications due to the difference in the circumstances of the player and the spectator. Even if a little reflection on our own experience did not lead as to realise this, we might dedace it easily from the general principle that action in idea is of the same psychological nature as action actaally carried out. As an example, let us take the feelings of the spectators of a football match. They will experience a reflection or reproduction of the feelings of activity experienced by the players and will also experience the pleasure which accompanies the sudden variations in the activity which are called forth by the uncertain requirements of the game. Such feelings of activity are always pleasurable when they are not out of due relation to the bodily strength. In the players fatigue may overcome the more pleasurable state, bat in the spectator, since the feeling is not of actual, bat only of incipient action, there is no danger of this revulsion. The resulting state of mind has also more of the character of feeling than of the conscionsness of action; bnt still the two states are essentially of one kind. The feelings of the spectator will never he as intense as those 
of the player, and in some cases, from their less variation and their clearer definition as feeling, they may even lose their pleasurable character more quickly. Supposing that there is no over exertion in the players, the rapid and nnexpected rariations of activity seem ever to give rise to fresh delight. The consciousness of the spectators does not realise this pleasure in its freshness and variety. It has more of the character of feeling proper, and may at length grow wearisome through monotony. It is a character of all feelings, however pleasant in their first experience, that when once fully realised as such, they have a tendency to decline. The pleasures that we can clearly anticipate are never keenly enjoyed in experience.

We will assume, then, that the interest of spectators takes its rise from the same source as that of the players, and that whatever we may have to say of games and sports, psychologically considered, will hold good, with dne modification, for both classes. But whilst in some games the two characters can hardly be discriminated, and the experiences of both are so much alike that it matters little in which relation a person may turn his attention to them, in others the experience of the players is very much affected by the severe and exhausting nature of the necessary action, and it is in these cases that there is the most marked difference between the feelings of the two classes. We might, therefore, make the amount and intensity of the action involved the basis of a classification; so we should have the best chance of scratinising the whole range of the states for the sake of which men engage in sports. Probably no one will deny the topcost place in this classification to the various athletic contests which are common amongst our own countrymen, as, for instance, foot races and boat races. It is not exactly easy to say what are the motives which sustain men in such pursuits. They are not universal amongst mankind. Althongh in this conntry we take them as matters of ordinary course, they have sometimes, in the mind of the intelligent foreigner, excited a suspicion of our national sanity. Taken by theruselves they can hardly be said to be pleasurable to those who take an active part in them. Indeed, in any contests worthy of the name, the severity of the exertion is generally prolonged until the discomfort and pain grow to a pitch almost beyond endurance, and certainly beyond the endurance of our ordinary moments when no other strong impulses are sustaining our efforts. Probably no one will admit this sooner than those who have habitually engaged in sach exercises.

Whence comes the exciting and sustaining impulse? Possibly from the pleasure in mere activity, such as a child has; but this commonly only for adults on whose activity circumstances in general places a very unusual restriction, for I am speaking not of moderate 
exercises, but of violent and severe efforts. Habit alsc may lead to what we may call an appetite for some special mode of long practised activity; but these canses alone can hardly account for the passion for the severe physical exercises and contests which make so large a show in modern life. To explain their attractiveness we must imagine, I think, a special pleasure which accompanies any exercise of our extreme powers whether bodily or intellectual, and one also quite distinct from that which accompanies exercise of a normal and moderate kind; any effort which appears to place us in relation to our environment superior to our ordinary relation, and this we find in the pleasure accompanying. Mr. Matthew Arnold has pointed out how great is the temptation in spiritual and intellectral matters to what he calls excessive self affirmation, and it seems that there is also in buman nature a great liking for bodily self affrmation or realisation. It is a fact of human nature, which no one hardly can have failed to observe, that the individual mind is greatly affected by its habitual relations to its surroundings. The number and range of our joys and sorrows, of our exaltations or despondencies, which after all are merely relative states arising by way of contrast to the ordinary background of consciousness, do not perhaps depend so much on lasting relations as on fluctnating circumstances and accidents, which come alike to all sorts and conditions of men, and pretty equally to all, bat the more constant relations arising from bealth, strength, and beanty, or even from the more artificial advantages of wealth and social position, have an all-powerful influence in shaping the more fundamental and constant parts from self-conscionsness. If then we can change this basis of consciousness by improving any apparently permanent relation to our surroundings, the pleasure gained is not merely a fleeting one, bat a deep and lasting satisfaction which is more than an equivalent for some intermingling pain experienced at the moment. To the nature which can aim at and realise this higher satisfaction men instinctively give honour, even though it is manifested in apparently worthless or bratal exercises. In the bulldog pluck, which dies bat never admits its inferiority to any overwhelming force, we English have chosen as one of our ideals an instance of this instinct of self affirmation. It seems to be a perpetual craving of the human mind to falfil and enlarge the possibilities of its being. Again and again it reappears in History. We may attempt to meusure the instinct by regarding some of its results, but

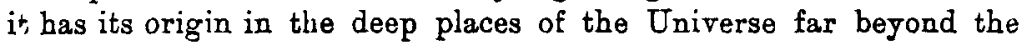
view of Science. The triumph of the Athlete in his supremest effort, agony though it also be, the glory of the thinker in the advance of his intelligence, and the delight of the Artist in his increasing skill, are all examples of the satisfaction of the same impulse mani- 
festing itself in strong minds of different characters. In ordinary lives, after the first flush of youth, when the normal growth of mind "nd body has ceased, there is perhaps little enough evidence of its presence. In the thinker and the artist it cannot be satisfied ander the same conditions as for the atblete. The vulgar strong excite. ment of contest is fatal to the finer kiuds of thought and feeling, as well as to long sustained silent and sympathetic rummunion with the objects of thought or representation. Ability for the lower physical effort - though it also is in its own way at the same time a spiritual effort-is however a more common heritage of mankind, and the satisfaction of superior performance is more easily attainable in this way, just as the delights of the senses can be realised by nearly all bat the higher pleasures of thought and feeling by few only. Hence in common men the instinct tends strongly to seek some physical accomplishment for its satisfaction.

In Athletic contests there is, however, as I have said, a painful accompaniment snfficient not only to deter the more sensitive from such exercises, but also to weaken all performance not sustained by other stimulation.

The presence of crowds of interested spectators and the excitement of actual contest are the necessary couditions of the most successful efforts of Athletes, because they add the stimalns necessary to counteract the restraining power of pain, and hence some curious results have worked themselves out.

The forms of contest which have prevailed at all periods bave been those which could be viewed by large bodies of men. We have heard often of hermits and recluses becoming great thinkers or artists, but never, I think, of one who has broken the record, say, for a ten-mile run, by a solitary race against time. And it will be found a true law, I think, that the nearer the exercise may be to the physical end of the scale the more necessity there is for the stimula. tion which comes from the presence of sympathetic crowds. So great indeed is this necessity that every artifice is resorted to to urouse interest in spectators. I read lately in an evening paper that on last Sunday week four men started from Kennington to walk to Epsom and back for wagers, and that large crowds gathered to watch them, becanse, instead of walking in the ordinary way, two of the men wheeled barrows, the third carried a bottle on his head, and the fourth walked with an 8-1b. damb-bell in each hand. Such races it is said frequently happen in London.

The contests which are most common are, as I have said, tbose which can be easily witnessed by large crowds, and can also be understood and appreciated by them. Running, rowing, and walking 
races are much more frequent and more eagerly contested than any other exercises, which, as they may give scope for greater cultivation and skill, might be supposed to be more interesting, bat fail in that respect because their performance cannot be fully seen: at any distance, and also because they are too far removed from the ordinary activities of life for their skilfal performance to be keenly appreciated by the general body of spectators. It is true that the most popular sports have perhaps an apparently more direct relation to atility than others which depend on acquired skill, bat this is not. so much the reason of their popularity as the fact that they are readily appreciable by masses of spectators. An exercise which not. only involved a painfal degree of exertion, bat also failed to interest spectators, could never become usual. On this principle I think we may account for the greater popularity of cricket and football aboveall other ball games-their action is on such a scale as to be easily visible at a distance, and is of a kind that can be realised, to some extent at least, by nearly every one.

I have, perhaps, in these remarks laid undne stress on those sports which involve some painfal feeling-neglecting those in which manifestly men engage as pleasurable in themselves. The occasion of these in early life is the necessity for some outlet for the superabndant nervous energy, and, in later life, the necessity for variation of activity which is often rendered monotonons, or is undaly curtailed hy the relations into which men are forced by the course of events.

To a great extent, and especially in the simple forms, these sports are due chiefly to what may be termed an appetite for activity. The man who paces up and down some restricted walk derives little positive pleasure from the activity, but he satisfies the mere craving for action which is so strong in all haman beings. In games in which more or less skill is involved there is, besides, the feeling of more complete self-realisation-an enlargement of the idea of self which by competition with others and by their record of observation acquires an objective reality which would otherwise be impossible. A little reflection will show us that the notion of self is made up of an aggregate of ideas of relations to an environment of certain types or standards, which in every society and in every physical situation we find as parts of our direct consciousness. Self is the sum of the modes in which we realise our existence measured by these types and standards-our habital modes are certainly of chief consequence. bat also any exceptional achievements have a great effect, especially if, by some visible mark or symbol, a lasting mewory of them can be established. Hence the value men set on prizes, crosses, titles of homnar. 
I have dwelt on this point because in the ordinary empirical psychology it is usual to impute the feeling of satisfaction which accompanies any successful exertion either of body or mind to a sense of the inferiority of others, or even to the realisation of their discomfiture. This, however, hardly seems credible. Could the spectators of some feat of strength or skill give their hearts applause to a man whose main feeling was one of superiority to themselves. Could there be any friendily feeling between competitors, if the feelings of the victor were, and wert known to be, simply feelings of exultation at the defeat of others.

The old custom of the prize ring, that before two pugilists commenced to fight they shook hands, indicates more truly, as I beliere the actual nature of the feelings both of rictor and vanquished. The triomph of the conqueror is a feeling of satisfaction in the realisation of his strength and skill-bat not a mere feeling of pride at having beaten his rival, far less mere satisfaction at his defeat; nor is it at all inconsistent with a feeling of considerable satisfaction on the part of the vanquished at having faced so severe a discipline. The feelings of the two are not different or opposite in quality but differ rather in degree only.

Besides the same feeling may exist where there is no contest. The strong man may glory in his strength and courage in climbing mountains, or in undergoing hardships and facing danger in lonely hunting expeditions. Thongh such delights are confined to exceptional natures, they are nevertheless illustrations of the law that I have tried to suggest, that what gives pleasure is an enlarged realisation of self, or a more complete realisation than the ordinary circumstances of life would otherwise allow.

In analysing the emotions of activity Professor Bain speaks much of what he calls the emotion of pursuit, or sometimes of a plot interest, terms which seem to me very vague and not suggestive of any definite feelings which we can recognise in consciousness. As instances of this custom he quotes the feelings of the hunter as he nears his quarry or of the beast of prey pursuing its victim. A little reflection will, I think, convince as that this is a very insufficient record of the pleasure of field sports.

The one thing that seems necessary to arouse interest is some object, of which the movements cannot be anticipated, and gire rise to ever varying exercise on the part of the sportsman. It is true perhaps that, arged by hunger, the tiger springs with all its might upon its prey, bat if we watch a cat or kitten playing with a mouse we see at once that the desire of bringing down its rictim is by no means a strony motive. It is caught only to be released and pursued 
again and again ; even after it is dead it is often thrown about as a mark for activity in renewed pursuit.

Men have devised numbers of games played with balls; one and all depend for interest in the movements of the ball, which in themselves are quite uninteresting, but furnish, as the ball bounds or rolls hither and thither, an object towards which an endless variety of actions can be directed.

The same purpose is falflled in field sports by the animal hunted for its life. A fox which for a time outstrips the hounds and donbles bither and thither, birds which suddenly rise, a fish which may at any moment rise at a fly, all serve the sarne object, and, as their movements are even less to be realised in anticipation than those of a ball, the movements of which depend upon a player, so they are the most perfect incentives to fresh and varying activities. Just as ordinary feelings long sustained in consciousness or fally realised in anticipation lose their pleasurable character, so actions which can be anticipated or are long unvaried not only cease to please but are even tiresome or painful.

So much for the emotion of parsuit.

So also Professor Bain considers as a pleasant element in field sports the satisfaction of the end of the action, i.e., the capture of the object of pursuit. From what has been said we see that this is hardly realised. The desire of capture is not itself the chief mutive of the sportsman. We may have some traces still left us of the feelings of savage ancestors who lived by hunting, and to whom the capture of prey was the opportnnity of satisfying bunger, but to most people the end of the chase simply means the end of the pleasure which it has aroused.

I should have liked to have been able in this paper to show how the same laws bold good even for games so different as card games are from Athletics. Card games perhaps only by a stretch of language can be called active amasements. There is no doubt that the states of mind of the players take on the character of cognitions rather than of volitions, but the same characters are combined to some extent even in the simplest field sports, and I believe the same laws would be found to hold good for both classes.

We are apt in considering volitions to look only at those of which actual moreinent is the most striking cbaracter, but on this method we should class higher as volitions the actions of the private soldier, who performs laborious marches and charges the enemy, than those of the General, who, sitting at his head-quarters, by his telegraph wires, controls the movements of vast armies.

In sport and play as in all other conditions our mental states men are at cnce Volition and Cognition and Feeling-sometimes one character 
predominates, sometimes another. What man seeks in amusement is to fill up the vacant possibilities of his consciousness, and sometimes it is consciousness of one character and sometimes of another that he seeks. The handicraftsman, tired of monotonous action, will commonly turn to books and intellectual amusements. The tired thinker to some active exercise, however simple. The conntryman, who has his full share of outdoor activity in ordinary life, loves nothing so much as to have his feelings aroused by a blood-curdling melodrama.

SYMPOSIUM-THE NATURE OF FORCE.

I.-By G. Johnstone Sronar, D.Sc., F.R.S., Vice-President of the Royal Dublin Society.

[Abstract.]

Pari I. Introductoby. Meteod and Postulates of the Inquiry.

Progress in ontology, as in other subjects of study, must start from the existing beliefs in the mind of the inquirer, or from some of them.

If the beliefs thus made the basis of a first investigation have been chosen with judgment, the inquirer will find himself, after he has traced their legitimate consequences, in a better position to review all his ontological beliefs and to amend them, before proceeding to take a further step of a like kind. This is the only process whereby, when repeated as often as may be necessary, any individaal mind can make sound progress.

The following are the beliefs which are treated as fundamental in the present essay. The reader is requested to accept them as postulates while he is occupied with it. He may afterwards make any or all of them the subject of a further inquiry, with the advantage of knowing what consequences they involve. If they stand this scrutiny, and if the scruting is a sufficient one, they will become related to the present inquiry as lemmas and will cease to be postulates.

\section{Postulates.}

1st belief.-That my present thoughts exist.

Definition 1.-The term thought is taken in its widest extension. It is to be understood as embracing everything of which we are conscious. 